third of the uterine blood supply. And the ligation of the uterine artery as it courses along the sides of the uterus from fundus to neck, will cut off as much blood supply as is compatible with the life of the uterine tumor. My operation was performed in the same month, November, 1892, as Dr. Martin's. Both were done independent of each other. They are the only means by which the blood supply of the myomatous tumor can be controlled. It is known to observing gynecologists that uterine myomata have not a very vital growth. They often become absorbed without any treatment. A shock, attendant on opening the abdomen, may induce a myoma to atrophy. Pregnancy frequently causes them to disappear during and after the puerperium. A slight change in the blood current will many times be sufticient to reduce a myoma. But when a definite nourishing blood current is suddenly cut off together with functionating tubes and ovaries, as in the operation I offer, it will be frequently sufficient to cure the myoma by atrophy. Hundreds of myomata have been cured, at least symptomatically, by ligating off the tubes and ovaries, but my operation proposes to cut off a supply of blood much greater than the ovarian artery. In fact, one can cut off as much blood supply from the myoma as his judgment dictates, by ligating the artery along the side of the uterus toward the internal os. A woman is more shocked and mutilated by the removal of the large uterus than she is by removal of the appendages, and the additional manipulation necessary to the ligation of the artery along the uterine sides is very little.

The operation I propose will not suit all cases to avoid abdominal hysterectomy. The operation which Dr. Martin offers will not fit every case. But by judging each case on its individual requirements, $I$ believe that one of the two operations which look to the control of blood supply will fit many cases which previously submitted to hysterectomy-with much risk. We hope your editorial, which notes that the only real curative method is the removal of the tumor, will be superseded by the operation which cures the tumor without removal-by atrophy. Cut off the blood stream that feeds an unnecessary district and it must check further growth and result in shrinkage. It should never be forgotten that an unlimited ligation should not be practiced, as gangrene may follow.

I have noticed during the past year, while examining fibroids per vaginam and by abdominal section, that some portion of the tumor was being fed by an enlarged and dilated artery, e.g., one of the ovarian or one of the uterine arteries were considerably enlarged. The most frequent (on account of opportunity and accessibility) I found was one of the uterine arteries excessively enlarged. I would often find on one side of the uterus (the side of the most enlargement), the uterine artery dilated and beating almost like the femoral. The plan of the operation is to ligate that dilated artery, which is growing a tumor, whether it be ovarian or uterine.

Respectfully,

F. Byron Robinson, Chicago.

\section{Analyses of "Cerebrine" and "Medulline."}

To the Editor:-At a meeting of the Chemical Section of the Chicago Academy of Sciences, held two months ago, Prof. M. Delafontaine of this city, presented some facts regarding tests of the substances known as "cerebrine" and "medulline," and somewhat more in detail than in the note in the Jourval of August 26. This work having been criticised in certain quarters, both as regards methods and conclusions, I thought it worth while to make a new examination of the question, avoiding as far as possible sources of error. I accordingly obtained from a well-known Chicago druggist a bottle of each of the two Hammond preparations which I tested, with results agreeing fully with those of Prof. Delafontaine. These tests I considered, however, only as preliminary to more extended ones. For the fuller tests I secured through one of our leading wholesale drug houses four bottles of "cerebrine" and four bottles of "medulline" direct from the Columbia Chemical Co., 90 South Fifth Ave. These bottles came packed in a small box which was handed to me unopened. Each small blue bottle was in a dark red pasteboard carton, labeled, "Sterilized Solution of "Cerebrine" and "Sterilized Solution of Medulline," with the name "William A. Hammond," in fac simile printed diagonally across it in red ink. The cartons had not been opened, which was shown by the unbroken labels. The bottles themselves were sealed with some kind of white wax, apparently paraffine, and were each found to contain about four cubic centimeters of a sweetish liquid consisting mainly of glycerine and alcohol.

I carried out special tests as follows:

The contents of two bottles of "cerebrine", were poured into a small fiask and extracted with pure benzol in two operations, using twenty cubic centimeters each time. The united extracts were evaporated spontaneously; a small oily residue left was treated with water, warmed on the water bath and used for tests. A portion of this aqueous mixture gave a strong test for nitrates with diphenglamine and sulphuric acid; another portion gave the nitrate test with ferrous sulphate and sulphuric acid. Another portion failed to give the nitrite test with naphthylamine and sulfonitic acid. The remainder of the aqueous liquid was saponified with sodium hydroxide and then tested for nitrates and nitrites, both of which were found in decided quantity. The benzol, sodium hydroxide, sulphuric acid and acetic acid used in these tests were pure and free from even traces of nitrates or nitrites, as I found by careful special examination.

The reactions given above show the presence of an organic nitrate (not nitrite) in the liquid, and the behavior on saponification is strongly suggestive of nitroglycerine. The fact of the solubility of this nitrate in pure benzol is impor$\tan t$.

I next dissolved the contents of one bottle of "cerebrine" in ten cubic centimeters of water and made tests for alka. loidal bodies. With solutions of mercuric-potassium iodide and iodine in potassium iodide, no precipitation whatever occurs. Platonic chloride, picric acid and phosphomolybdic acid give a very slight haziness; with mercuric chloride a marked cloudiness is produced. These tests I consider sufficient to show the absence of animal or other alkaloids.

Four bottles of "medulline"were next mixed and extracted with pure benzol; an oily residue remained on evaporation of the benzol. This residue was dissolved in alcohol and treated with ammonium sulphid. A finely divided precipitate of sulphur settled out. The excess of ammonium sulphid was removed with pure zinc sulphate, and the filtered liquid tested for nitrites; a strong reaction was obtained. This test, like those given above for the "cerebrine" is characteristic of nitroglycerin and strengthens those obtained in my preliminary tests. Taking all tests into consideration, I am of the opinion that the preparations, "cerebrine" and "medulline," contain nitroglycerin as their active ingredients, as stated by Delafontaine and others.

$$
\text { Yours truly, J. H. LoNG. }
$$

Northwestern University Laboratories.

\section{Uterine Fibroids.-A Correction.}

To the Editor:-In my letter in the Journal of Dec. 23, 1893, two errors occur, caused by carelessness in copying 